\section{IMPLICACIONES PARA LA GESTIÓN DE EMERGENCIAS BASADAS EN LA OCURRENCIA DE DESASTRES EN CENTROS TURÍSTICOS DE MÉXICO ENTRE EL 2000 Y 2018}

Felipe de Jesús Juárez Villanueva ${ }^{1, *}$

\section{RESUMEN}

Los desastres son un conjunto de elementos integrados por riesgos, amenazas, vulnerabilidades, resiliencia y grados de exposición. Aunque existen fondos catastróficos para su atención, no siempre pueden dar cobertura a los eventos registrados. Con datos oficiales del periodo de enero de 2000 a junio de 2018, el presente artículo hace referencia a la ocurrencia de desastres geológicos e hidrometeorológicos a nivel municipal, donde se localizan diversos centros turísticos en México. Con base en lo anterior, los objetivos del trabajo son: caracterizar la ocurrencia de desastres en centros turísticos en México; e, identificar las implicaciones del manejo de emergencias y desastres según señala la Ley General de Protección Civil. Además, el texto comparte reflexiones basadas en experiencias personales obtenidas en el manejo de emergencias y desastres, enfocadas en la toma decisiones, y la incorporación de medidas de prevención para disminuir principalmente la vulnerabilidad organizacional y la resiliencia empresarial de una agencia de viajes.

\section{PALABRAS CLAVE}

Desastres, Centros turísticos, prevención de desastres, manejo de emergencias, México

\section{IMPLICATIONS FOR EMERGENCY MANAGEMENT BASED ON THE OCCURRENCE OF DISASTERS IN TOURIST DESTINATIONS OF MEXICO BETWEEN 2000 AND 2018}

\section{ABSTRACT}

Disasters are a set of elements composed of risks, hazards, vulnerabilities, resilience and exposure. Although there often are disaster recovery funds, these are never enough to meet the needs of people. Based on official data from 2000 to 2018, this work looks at the occurrence of geological and hydrometeorological disasters affecting tourist destinations at the municipal level in Mexico. Therefore, the objectives of the study are: to characterize the occurrence of disasters on tourist destinations in Mexico, as well as the types of phenomena that have affected them; and, to identify certain implications for the emergency and disaster management according to the General Law of Civil Protection. In addition, the paper offers some reflections based on personal experiences on disaster and emergency management. These focus on decision-making, and the introduction of preventive measures to reduce organizational vulnerability and promote business resilience in the tourist sector.

\section{KEYWORDS}

Disasters, Tourist destination, disaster prevention, emergency management, Mexico
1. Maestría en Docencia para la Educación Media Superior, Facultad de Filosofía y Letras, Universidad Nacional Autónoma de México, Ciudad de México, México.

*Autor de correspondencia: geofel19@hotmail.com

\section{RECIBIDO}

28 de septiembre de 2018

\section{ACEPTADO}

28 de noviembre de 2018

\section{PUBLICADO}

1 de enero de 2019

\section{Formato cita}

Recomendada (APA): Juárez Villanueva, F.J. (2019). Implicaciones para la gestión de emergencias basadas en la ocurrencia de desastres en centros turísticos de México entre el 2000 y 2018, Revista de Estudios Latinoamericanos sobre Reducción del Riesgo de Desastres REDER, 3(1), pp.85-101.

\section{(C) $(1) \Theta$}

Todos los artículos publicados en REDER siguen una política de Acceso

Abierto y se respaldan en una Licencia CreativeCommons Atribución-NoComercial 4.0 Internacional.

\section{Revista de Estudios}

Latinoamericanos sobre Reducción del Riesgo de Desastres (REDER)

Diseño: Lupe Bezzina Tipografía: Hospital 


\section{INTRODUCCIÓN}

En todo el mundo se mantiene latente la posibilidad de la ocurrencia de desastres, que son producto de diversas problemáticas asociadas al desarrollo económico, que indiscutiblemente tiene relaciones con el turismo. En este trabajo, se parte del principio de que ningún desastre debe ser concebido como producto exclusivo de la naturaleza, ya que "son la manifestación de riesgos no controlados" (Wilchaes-Chaux, 1998, p.18).

Gracias a la tecnología, los eventos de desastres pueden ser registrados en tiempo real, como sucedió el 23 de diciembre de 2018, derivado de la actividad volcánica del Krakatoa, se produjo un tsunami que golpeó la isla de Java en Indonesia, dejó una estela de daños en ese destino turístico: de más de 400 decesos y más de 1400 heridos (BBC, 2018).

En 2017, el volcán de Fuego en Guatemala, dio una de las mayores lecciones en torno a vivir en las inmediaciones de un cráter. Si bien, en Antigua, Guatemala, un complejo turístico fue afectado por la caída de ceniza, el personal del hotel puso en marcha el protocolo de evacuación del inmueble, sin que se reportaran pérdidas humanas: entre huéspedes, visitantes y empleados. Este destino recibe en promedio 1.5 millones de turistas al año, principalmente extranjeros. Los hoteles en el radio de posible afectación, tuvieron que suspender actividades hasta que la alerta fue levantada. En otros casos, los hoteles fungieron como refugios temporales (La Silla Rota, 2018).

El turismo en México, directa e indirectamente, emplea aproximadamente a 10 millones de personas: un $18 \%$ de la población económicamente activa del país (INEGI, 2018). Según SECTUR (2017b), en 2017, México recibió la visita de más de 39 millones de turistas internacionales, por lo cual se ubicó en 6to lugar a nivel mundial; Obtuvo 21 mil millones de USD por divisas, que posicionaron a México en el lugar 15 a nivel global (Notimex, 2018; SECTUR, 2017b).

El World Risk Report 2018 (BEH \& UNU-EHS, 2018) ponderó a México en el lugar 92 de 894 países, con un índice de riesgo 'alto', como producto de la exposición a peligros naturales (14\%); su vulnerabilidad (42\%) conformada por: 1) Capacidades de afrontamiento para reducir las consecuencias negativas (72\%); Capacidades de adaptación de estrategias a largo plazo (32\%); y 3) probabilidad de sufrir daño $(21 \%)$.

En México, la Ley General de Protección Civil (LGPC) ofrece una serie de conceptos que permiten comprender los elementos para entender los desastres: riesgo, vulnerabilidad y resiliencia, son la base conceptual. En documentos oficiales, los desastres ya no son concebidos como eventos de exclusivo origen natural, y el ser humano, tiene responsabilidad en su generación: es un cambio del enfoque dominante de desastres, hacia la llamada 'visión alternativa'. Pese a esa distinción, aún falta mucho por hacer, ya que la Ley General de Turismo (2018), no menciona los conceptos de vulnerabilidad y resiliencia. Según la LGPC:

"Un desastre es el resultado de la ocurrencia de uno o más agentes perturbadores de origen natural o humano, que, al acontecer en una zona, causan daños y que, por su magnitud, exceden la capacidad de respuesta de la comunidad afectada".

(LGPC, 2018, p.24)

En contraste, autores como Blakie et al., (1993); Calderón (2001); García (2005); Maskrey (1993); Oliver-Smith en FORIN (2014), coinciden en definir un desastre, como el resultado de riesgos no controlados. Los riesgos a su vez, evidencian amenazas socio-naturales, vulnerabilidades y grados de exposición de la sociedad. Por lo cual, un mismo destino será afectado de distinta manera. Para ello, sería necesario analizar las causas de fondo que generan la vulnerabilidad, y cómo se construyen los procesos de desastres.

En este trabajo entenderemos la 'emergencia' como una situación que puede causar un daño a la sociedad, generada o asociada con la presencia de un agente perturbador (LGPC, 2018, p.3)., El 'riesgo', por otro lado, se entienderá como las "pérdidas probables sobre un agente afectable" (LGPC, 2018, p.6): pudiera ser un destino turístico, un hotel, o los propios turistas. Es resultado de la interacción entre su vulnerabilidad y la presencia de un agente perturbador. Asímismo, la 'vulnerabilidad' será comprendida como la "susceptibilidad o propensión de un agente afectable, a sufrir daños o pérdidas ante la presencia de un agente perturbador" (LGPC, 2018, p.7), reconciendo por lo tanto que la vulnerabilidad es determinada por factores ambientales, físicos, sociales, económicos, políticos y culturales, donde la organización y comunicación son un eslabón. 
En este trabajo entenderán la 'resiliencia' como la "capacidad que tiene una comunidad que está expuesta a un peligro o agente perturbador, para resistir, asimilar, adaptarse y recuperarse de sus efectos en un corto plazo y de manera eficiente" (LGPC, 2018, p.6). Prospectivamente, se debe lograr una mejor protección y mejorar las medidas de reducción de riesgo. Lo cual tendría que involucrar necesariamente a la vulnerabilidad.

Así como para Wilchaes-Chaux (1998) existe una vulnerabilidad global dividida en: 1) Ambiental, 2) Social, 3) Económica; 4) Política, 5) Institucional; 6) Educativa, y otras más. También existe el concepto de 'resiliencia empresarial' que es integrado por: a) Preparación; b) Evento disruptivo; c) Primera respuesta; d) Impacto inicial; e) Impacto total; f) Preparaciones para la recuperación; g) Recuperación; h) Impactos a largo plazo. Para Song (2013) el incremento en la resiliencia de un lugar, emerge del decremento de su vulnerabilidad, y viceversa.

Las empresas resilientes tienen la capacidad de absorber cambios y rupturas, internas y externas, sin que sea afectada su rentabilidad, poseen flexibilidad que le permiten una rápida adaptación, e inclusive, logran obtener beneficios de situaciones de emergencia o desastre (Minolli en Sanchis \& Poler, 2011). En este sentido, no necesariamente se requieren situaciones de desastre, para perder el control ante una emergencia. Tampoco no siempre los empresarios más acaudalados tienen empresas resilientes.

Es importante considerar además que el sector turismo tiene la capacidad de modificar territorios, involucrándose en la planeación y ordenamiento territorial. De esta forma, el turismo podría aumentar el grado de exposición, incidiendo en la ocurrencia de desastres. En México y en otros lugares, entre más cercano esté un hotel al mar, más caros pudieran ser los servicios que se ofrezcan. Pero, en caso de un huracán, sismo, tsunami, u otro agente perturbador, el grado de exposición pudiera incrementarse, además, no siempre los destinos ofrecen a los turistas -ni a los propios empleados- la información básica para enfrentar una emergencia o un desastre. Si las autoridades locales son rebasadas para atender disrupciones en el resto del territorio, serán quienes viven del el turismo los actores claves que enfrenten esas emergencias y de ellos pudiera depender la vida de los turistas que visitan los destinos.

Con datos oficiales del periodo de enero de 2000 a junio de 2018, el presente artículo hace referencia a la ocurrencia de desastres geológicos e hidrometeorológicos a nivel municipal, donde se localizan diversos centros turísticos en México. Con esto, el estudio busca caracterizar la ocurrencia de desastres en centros turísticos en México e identificar las implicaciones del manejo de emergencias y desastres según señala la Ley General de Protección Civil. Hacia el final de este trabajo se compartirán algunas reflexiones basadas en experiencias personales obtenidas en el manejo de emergencias y desastres, enfocadas en la toma decisiones, y la incorporación de medidas de prevención para disminuir principalmente la vulnerabilidad organizacional y la resiliencia empresarial de una agencia de viajes.

\section{METODOLOGÍA}

El presente trabajo consistió en realizar una investigación exploratoria e interpretativa, sobre la ocurrencia de desastres publicadas en el Diario Oficial de la Federación (DOF) en municipios donde se localizan Centros Turísticos (CT) de SECTUR (2017b). La anterior información permitió identificar la frecuencia de eventos geológicos e hidrometeorológicos. Con esa información se realizaron tablas y figuras, para identificar los Centros Turísticos con mayor recurrencia de desastres en el periodo 2000 a 2018. Posteriormente, con base en una revisión principalmente de noticias y algunos estudios de caso, se contextualizaron algunos desastres. Posteriormente, se utilizaron como referencia algunas experiencias de emergencias y desastres vividas por el autor en el sector turismo en México. Con base en lo anterior se entrevistó a un especialista para determinar algunas implicaciones y responsabilidades en materia de protección civil, aplicables a prestadores de servicios e inmuebles destinados al turismo, en México. Se contrastó la información y al final se hizo una revisión del bono de desastres y su posible aplicación en los más de 300 desastres ocurridos en los CT.

\section{OCURRENCIA DE DESASTRES EN CENTROS TURÍSTICOS EN MÉXICO: 2000 AL 2018}

El propósito de esta sección consistió en responder tres interrogantes: 1) ¿Cuáles tipos de fenómenos naturales se relacionaron con las declaratorias de desastres?; 2) ¿Cuáles municipios han tenido mayor frecuencia de desastres?; 3) Contextualizar algunos casos críticos en centros turísticos. 
En el periodo que va desde el 2000 al 2018, se registraron 1.165 declaratorias en municipios con actividades turísticas: $62 \%$ de emergencias y $38 \%$ de desastres. Cabe señalar que los datos hacen alusión a la frecuencia, pero no al daño. Lamentablemente no existe un registro fiable sobre daños exclusivos en el sector turismo, que abarquen la misma temporalidad y profundidad como la del DOF. De esta forma, los datos fueron recabados principalmente de fuentes de prensa -noticias- y estudios de caso de eventos particulares.

En México, 82 municipios tienen 'Centros Turísticos'1. El sector turismo se vio afectado directa e indirectamente, ya sea por el cierre temporal para la reconstrucción; la cancelación de vuelos, reservaciones; daños en carreteras. Pero al ser bienes privados, los datos no son de dominio público, y las cifras son generales. Así como existen instituciones vulnerables, también existen hoteles, medios de transporte, agencias, restaurantes y demás instalaciones que presentan diversos grados de exposición, no necesariamente los 'más ricos' son menos vulnerables: ya sea física, social, organizacional, política o económicamente, es muy probable que un complejo turístico no sea afectado en su infraestructura, pero quizá las viviendas de sus empleados si lo sea.

\section{Fenómenos asociados a desastres}

El 89\% (392) de los desastres ocurrieron en 77 municipios con centros turísticos, y se relacionaron con: Lluvias 53\% (excluyen ciclones, huracanes y tormentas); Ciclones Tropicales 32\% (incluyen huracanes, tormentas tropicales); Sismos 8\%; e Inundaciones: 7\%. La Figura 1, permitió realizar las siguientes referencias:

- Lluvias: 208 en total, 66 municipios afectados.

- Ciclones tropicales: 124 declaratorias en total (27 Ciclones tropicales, 13 Tormentas tropicales), 46 municipios afectados.

- Inundaciones: 28 declaratorias que afectaron 18 municipios. Temporalidad: 11 años (58\% del periodo).

- Sismos: 32 declaratorias (2 en promedio), asociados a 13 sismos de magnitud entre 6.0 y $8.2 \mathrm{Mw}$, que afectaron a 19 municipios

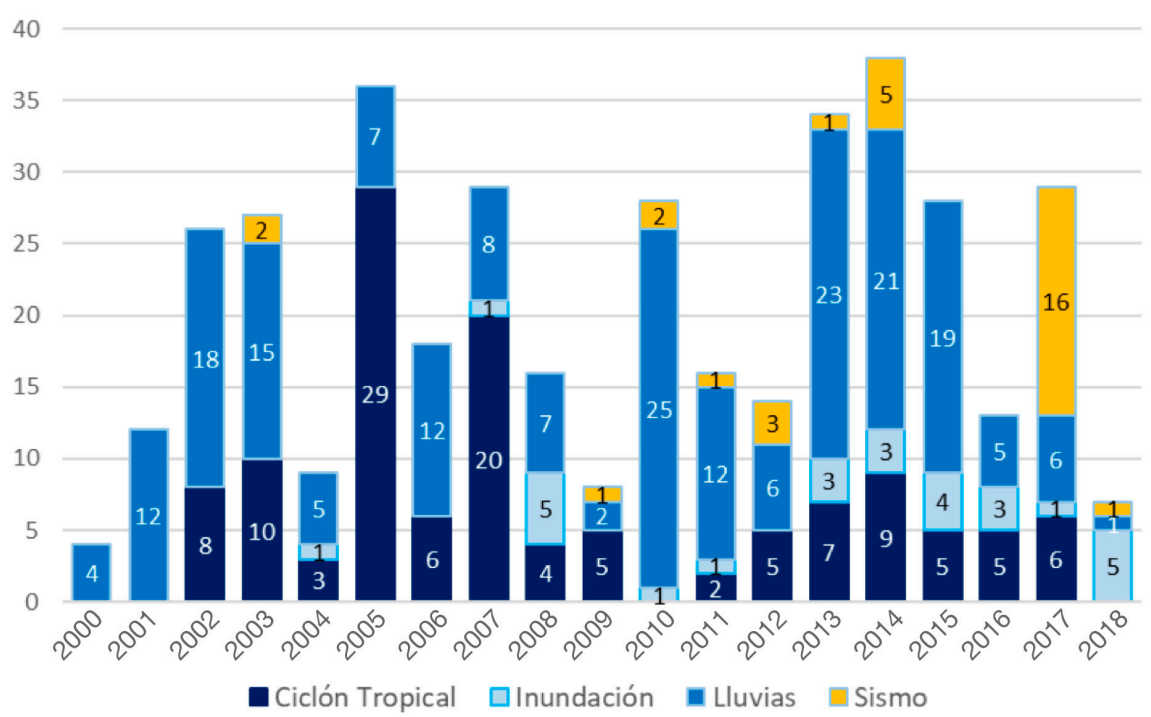

Figura 1. Declaratorias de desastres en municipios con Centros Turísticos en México 2000 a 2018 Fuente: Autor, 2019, basado en DOF del 2000 al 2018 (SEGOB, 2019)

\section{Desastres en municipios con centros turísticos en México}

En los municipios con centros turísticos en México que han tenido mayor frecuencia de desastres, los fenómenos más representativos fueron: ciclones, lluvias, inundaciones y sismos.

Ciclones tropicales, huracanes y tormentas tropicales

- 124 declaratorias de desastres

- Huracanes: 27
1. SECTUR (2018): Tener más de 2.000 cuartos de hotel; Es la capital del estado; Recibe en forma periódica flujos significativos de turistas; Es ciudad de la frontera norte que registra más de 3.5 millones de visitantes internacionales al año; Participa en algún programa de desarrollo de la secretaría de turismo; Constituye un complejo turístico integralmente planeado por el Fondo Nacional de Fomento al Turismo (Fonatur). 
- Tormentas tropicales: 13

- 46 municipios afectados pertenecientes a 15 entidades: Baja California, Baja California Sur, Campeche, Chiapas, Colima, Guerrero, Hidalgo, Jalisco, Nuevo León, Oaxaca, Quintana Roo, Sinaloa, Sonora, Veracruz, Yucatán.

- Los municipios con mayor frecuencia fueron: Loreto 11, La Paz 10, Los Cabos 8, en BCS; Manzanillo, Col. 8. Municipios que representaron al 30\% del total.

- La mayor frecuencia de desastres se relacionó con tormentas tropicales; seguida de huracanes categoría 2 y 4.

- $\quad$ El $68 \%$ de los desastres se asociaron a las categorías de tormenta tropical, y huracanes 1 y 2 .

Entre los casos críticos de huracanes están: Wilma y Stan en 2005, que afectaron principalmente la península de Yucatán; y Odile en 2014, que afectó principalmente a Los Cabos y distintos sitios de Baja California Sur (El Universal, 2017a).

El huracán Stan, en 2005, es considerado uno de los huracanes más costosos en la región de la península de Quintana Roo, ya que los daños superaron los $\$ 2.100$ millones de USD, con daños directos superiores al $65 \%$. En el caso de Chiapas, en algunas localidades la reconstrucción tardó más de 8 años (El Universal, 2017a).

Por su parte, el huracán Wilma, en 2005, afecto Quintana Roo: Cancun, Playa del Carmen, Cozumel e Isla Mujeres. La región afectada albergaba al 75\% de la población del estado y al $98 \%$ de la infraestructura hotelera. Los daños superaron los $\$ 1.740$ millones de USD -Palafox y Frausto (2008), Spring (2012), El Universal (2017a). Luego de este huracán, se realizó un levantamiento de 367 encuestas, aplicadas en Cozumel y Solidaridad. Más del 40\% de los encuestados perdió su empleo, la gran mayoría en hoteles, sumadas a agencias de viajes, restaurantes, taxistas, y otros prestadores de servicios. Si bien durante el primer mes hubo una mayor pérdida de empleos, esta se extendió hasta 5 meses (Palafox \& Frausto, 2008).

El huracán Odile de 2014 que afectó Baja California Sur, tuvo mayores afectaciones en Los Cabos, La Paz. El sector turístico resultó fuertemente dañado, los gobiernos federal y estatal transportaron a más de 30 mil turistas varados en San José del Cabo y Los Cabos: la gran mayoría provenientes de EEUU, que estuvieron hospedados en hoteles de cinco estrellas y de gran turismo. Vila M. (2005) menciona que, a diferencia de otros desastres, los procesos de reconstrucción se hicieron con mayor rapidez. Entre otros daños adicionales, estuvieron las instalaciones portuarias, restaurantes.

Paradójicamente, los hoteles más exclusivos, cuyo precio de habitaciones oscilaban entre $\$ 700$ y $\$ 800$ USD por noche, fueron los que tardaron más tiempo en reabrir sus puertas, debido al tiempo requerido para reacondicionar el lujo. De los más de 13 mil cuartos disponibles, después de Odile, el $2 \%$ estuvo en condiciones óptimas para alojar turistas. Entre septiembre a noviembre, las pérdidas económicas por la indisponibilidad de ocupación de las habitaciones, superaron el 1,6 millones de USD, a esto se le añade las pérdidas por consumo, que representaron más de $\$ 75$ millones de USD (Vila M., 2005).

\section{Sismos}

- 13 sismos magnitud entre 6,0 y 8,2 Mw.

- 32 declaratorias en 28 municipios con centros turísticos.

- 6,0 a 6,9 Mw: Acapulco Gro. (3); Comitán, Tapachula, Tonalá y Tuxtla Gutiérrez en Chia.; Taxco, Gro.; Huatulco, Oax.

- $\quad$ 7,0 a 7,9 Mw: Acapulco Gro.; Cuernavaca, Mor.; Colima, Col.; Manzanillo, Col; Mexicali, BC; Oaxaca Oax.; Puebla, Pue.; Puerto Escondido, Oax., Tapachula, Chia.; Taxco, Gro; Tecate, BC.; Tlaxcala, Tlax.

- $\quad$ 8,0 a 8,2: Coatzacoalcos, Ver.; Comitán, San Cristóbal de las Casas, Tapachula y Tonala, Chia.; Huatulco y Puerto Escondido, Oax.

- Los municipios con mayor frecuencia fueron: 12 Coatzacoalcos, Ver.; 12 Linares y 10 Monterrey en NL; 9 Xalapa, Ver.; 8 Durango, Dgo.; 7 Benito Juárez (Cancún), Q. Roo; 7 Boca del Río, Ver.; 7 Santiago, NL. El 35\% de todos los desastres de este tipo. 
Los sismos del 7 y 19 de septiembre de 2017, magnitudes 8,1 y 7,1 Mw respectivamente, acarrearon distintos efectos como son daños a caminos e infraestructura pública y privada. Como pocas veces había ocurrido, la particularidad de ambos sismos, fue las afectaciones colaterales al patrimonio natural y cultural. En el primer caso, las grutas de Cacahuamilpa, Gro., cerraron sus puertas, debido a la necesidad de inspecciones para determinar la viabilidad de su uso. Por su parte, las lagunas de agua azul en Chiapas perdieron gran parte de su caudal, y fueron los propios habitantes quiénes ante la nula respuesta de autoridades, removieron los escombros que obstruían el paso del agua, y con ello recuperar la normalidad del afluente. Asímismo, la zona arqueológica del cerro del Tepozteco también tuvo que cerrar sus puertas junto con Tlayacapan. Estos dos destinos son el motor turístico del estado de Morelos, y ambos fueron afectados considerablemente (Valle, 20017). En resumen, los destinos turísticos de importancia regional y algunos nacional, que sufrieron mayores daños fueron:
1. En Chiapas: Chiapa de Corzo y San Cristóbal de las Casas
2. En Puebla: Atlixco y Cholula
3. En Oaxaca: Mitla; Guerrero: Taxco
4. En México: Malinalco
5. En Morelos: Tepoztlan y Tlayacapan

En algunos casos, la afluencia de visitantes extranjeros y nacionales disminuyó hasta un $80 \%$. En la mayoría de estos destinos, quienes dependían de las actividades turísticas son guías de turistas, artesanos, u otros prestadores de servicios, tuvieron que cambiar de empleo. Ya que en algunos casos como se verá más adelante, pasó hasta un año para poder recuperar la afluencia de turistas (Ballesteros, 2017; El Universal, 2017b).

Los daños al patrimonio cultural se extendieron a más de 1.450 inmuebles: más del 90\% fueron monumentos históricos, el resto fueron museos y sitios arqueológicos. Oaxaca, México, Puebla y Morelos superaron los 1.000 inmuebles. Tan sólo para su reacondicionamiento, en 2017 la Secretaría de Cultura estimaba un monto de $\$ 40$ millones de USD (Esquivel et al., 2018).

\section{Grado de desastres en municipios con Centros Turísticos en México}

Con base en la información precedente, se realizó un ejercicio para ponderar cuáles de esos centros turísticos están localizados en municipios donde han ocurrido más desastres. Cada tipo de fenómeno fue ponderado en cinco grados. Los criterios de asignación tomaron como base la opinión del ex personal que ha trabajado durante 20 años en la atención a emergencias muy de la mano con la protección civil. De esta forma, se identificaron las frecuencias mínimas y máximas:

- Ciclones: 1 a 11 (cinco grados: muy alto, alto, medio, bajo y muy bajo)

- Lluvias: 1 a 12. (cinco grados: igual que el anterior)

- Inundaciones: 1 a 4 (cuatro grados: exceptuando el grado medio)

- Sismos: 1 a 4 (cuatro grados: exceptuando el grado medio).

- Declaratorias de desastres: 392

- $\quad$ El 35\% de los municipios tiene frontera directa al mar

La Figura 2, permite identificar los porcentajes del grado de desastres de los distintos municipios con Centros Turísticos en México. A estos datos se le incorpora el número de municipios con declaratorias de desastres, según el grado:

- Muy alto: 12 municipios concentraron el 39\% de las declaratorias. El 75\% de los municipios tiene frontera al mar.

- Alto: 8 municipios fueron escenario del $19 \%$ de las declaratorias. El $50 \%$ de los municipios tiene frontera al mar.

- Medio: 15 municipios se relacionaron con el $22 \%$ de las declaratorias. El $33 \%$ de los municipios tiene frontera al mar.

- Bajo: 24 municipios representaron el $16 \%$ de las declaratorias. El $29 \%$ de los municipios tiene frontera al mar. 
- Muy bajo: 18 municipios equivalen al $5 \%$ de las declaratorias. El $11 \%$ de los municipios tiene frontera al mar.

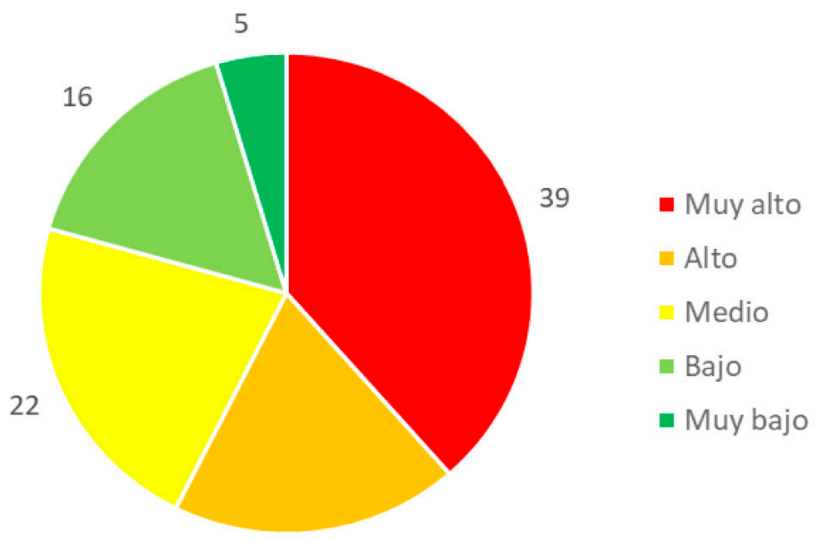

19

Figura 2. Grado de frecuencia de desastres en municipios con centros turísticos en México entre el 2000 y 2018 Fuente: Autor, 2019, basado en DOF del 2000 al 2018 (SEGOB, 2019)

La Tabla 1 pondera cada uno de los 77 municipios que albergan centros turísticos, incluye la frecuencia de ciclones, lluvias, inundaciones y sismos, además de la ponderación de los grados de ocurrencia: muy alto, alto, medio, bajo y muy bajo. Dicha tabla se relaciona con la Figura 3. Grado de ocurrencia de desastres en municipios con centros turísticos en México.

\begin{tabular}{|c|c|c|c|c|c|c|c|c|c|}
\hline Clave & Municipio & Entidad & Huracanes & Inundaciones & Lluvias & Sismos & Total & Grado & Color \\
\hline 65 & Coatzacoalcos & Veracruz & 2 & 2 & 12 & 1 & 17 & Muy alto & \\
\hline 6 & Loreto & Baja California Sur & 11 & & 3 & & 14 & Muy alto & \\
\hline 7 & La Paz & \begin{tabular}{|l} 
Baja California Sur \\
\end{tabular} & 10 & 1 & 3 & & 14 & Muy alto & \\
\hline 26 & Acapulco & Guerrero & 2 & 3 & 4 & 4 & 13 & Muy alto & \\
\hline 40 & Linares & Nuevo León & 1 & & 12 & & 13 & Muy alto & \\
\hline 16 & Tapachula & Chiapas & 3 & & 6 & 3 & 12 & Muy alto & \\
\hline 41 & Monterrey & Nuevo León & 1 & & 10 & & 11 & Muy alto & \\
\hline 64 & Xalapa & Veracruz & 4 & & 9 & & 13 & Muy alto & \\
\hline 33 & Benito Juárez & Quintana Roo & 3 & 1 & 7 & & 11 & Muy alto & \\
\hline 65 & Boca del Río & Veracruz & 2 & 2 & 7 & & 11 & Muy alto & \\
\hline 5 & Los Cabos & \begin{tabular}{|l} 
Baja California Sur \\
\end{tabular} & 8 & & 3 & & 11 & Muy alto & \\
\hline 51 & Cozumel & Quintana Roo & 4 & 1 & 6 & & 11 & Muy alto & \\
\hline 12 & Manzanillo & Colima & 8 & & 1 & 1 & 10 & Alto & \\
\hline 50 & \begin{tabular}{|l} 
Isla Mujeres \\
\end{tabular} & Quintana Roo & 4 & 1 & 5 & & 10 & Alto & \\
\hline 49 & Solidaridad & Quintana Roo & 4 & 1 & 5 & & 10 & Alto & \\
\hline 43 & Oaxaca de Juárez & Oaxaca & 1 & 1 & 6 & 2 & 10 & Alto & \\
\hline 42 & Santiago & Nuevo León & 1 & 1 & 7 & & 9 & Alto & \\
\hline 22 & Durango & Durango & & 1 & 8 & & 9 & Alto & \\
\hline 45 & Santa Maria Huatulco & Oaxaca & 3 & & 3 & 2 & 8 & Alto & \\
\hline 17 & Tuxtla Gutiérrez & Chiapas & 1 & & 4 & 3 & 8 & Alto & \\
\hline 60 & Guaymas & Sonora & 4 & & 3 & & 7 & Medio & \\
\hline 59 & Hermosillo & Sonora & 3 & & 4 & & 7 & Medio & \\
\hline 13 & Tonalá & Chiapas & 4 & & 1 & 2 & 7 & Medio & \\
\hline 9 & Piedras Negras & Coahuila & & & 6 & & 6 & Medio & \\
\hline 36 & Rosario & Sinaloa & 2 & & 4 & & 6 & Medio & \\
\hline 61 & Centro & Tabasco & & 4 & 2 & & 6 & Medio & \\
\hline 11 & Colima & Colima & 4 & & 1 & 1 & 6 & Medio & \\
\hline 21 & Chihuahua & Chihuahua & & 3 & 2 & & 5 & Medio & \\
\hline 75 & Juárez & Chihuahua & & 2 & 4 & & 6 & Medio & \\
\hline 14 & Palenque & Chiapas & 1 & & 4 & & 5 & Medio & \\
\hline 44 & San Juan Bautista Tuxtepec & Oaxaca & 2 & & 2 & 1 & 5 & Medio & \\
\hline 76 & San Pedro Mixtepec -Dto. 22 - & Oaxaca & 2 & & 1 & 2 & 5 & Medio & \\
\hline 62 & Tampico & Tamaulipas & & & 5 & & 5 & Medio & \\
\hline 52 & Tulum & Quintana Roo & & 1 & 4 & & 5 & Medio & \\
\hline 27 & Zihuatanejo de Azueta & Guerrero & 2 & & 3 & & 5 & Medio & \\
\hline 57 & Ahome & Sinaloa & 1 & 1 & 2 & & 4 & Bajo & \\
\hline 35 & Puerto Vallarta & Jalisco & 3 & & 1 & & 4 & Bajo & \\
\hline 15 & San Cristóbal de las Casas & Chiapas & 1 & & 2 & 1 & 4 & Bajo & \\
\hline 8 & Campeche & Campeche & 2 & & 1 & & 3 & Bajo & \\
\hline 56 & Culiacán & Sinaloa & 1 & & 2 & & 3 & Bajo & \\
\hline 54 & Escuinapa & Sinaloa & 1 & & 2 & & 3 & Bajo & \\
\hline 29 & Huasca de Ocampo & Hidalgo & 2 & & 1 & & 3 & Bajo & \\
\hline 58 & Mazatlán & Sinaloa & 1 & & 2 & & 3 & Bajo & \\
\hline 30 & Mineral del Monte & Hidalgo & 2 & & 1 & & 3 & Bajo & \\
\hline 31 & Pachuca de Soto & Hidalgo & 2 & & 1 & & 3 & Bajo & \\
\hline 72 & Sombrerete & Zacatecas & & & 3 & & 3 & Bajo & \\
\hline 25 & Taxco & Guerrero & & & 1 & 2 & 3 & Bajo & \\
\hline 18 & Comitán & Chiapas & & & & 2 & 2 & Bajo & \\
\hline 55 & El Fuerte & Sinaloa & 1 & & 1 & & 2 & Bajo & \\
\hline 4 & Ensenada & Baja California & 1 & & 1 & & 2 & Bajo & \\
\hline 34 & Guadalajara & Jalisco & 1 & & 1 & & 2 & Bajo & \\
\hline 20 & Hidalgo del Parral & Chihuahua & & 1 & 1 & & 2 & Bajo & \\
\hline 74 & Jerez & Zacatecas & & & 2 & & 2 & Bajo & \\
\hline 46 & Puebla & Puebla & & & 1 & 1 & 2 & Bajo & \\
\hline 73 & San Juan del Río & Querétaro & & & 2 & & 2 & Bajo & \\
\hline
\end{tabular}

(Continúa en la siguiente página) 
(Continuación)

\begin{tabular}{|c|c|c|c|c|c|c|c|c|}
\hline 68 & Santa Elena & Yucatán & 2 & & & & 2 & Bajo \\
\hline 2 & Tijuana & Baja California & & & 2 & & 2 & Bajo \\
\hline 67 & Tinum & Yucatán & 2 & & & & 2 & Bajo \\
\hline 70 & Valladolid & Yucatán & 2 & & & & 2 & Bajo \\
\hline 0 & Aguascalientes & Aguascalientes & & & 1 & & 1 & Muy bajo \\
\hline 39 & Bahía Banderas & Nayarit & & & 1 & & 1 & Muy bajo \\
\hline 24 & Celaya & Guanajuato & & & 1 & & 1 & Muy bajo \\
\hline 38 & Cuernavaca & Morelos & & & & 1 & 1 & Muy bajo \\
\hline 28 & Huichapan & Hidalgo & 1 & & & & 1 & Muy bajo \\
\hline 69 & Mérida & Yucatán & 1 & & & & 1 & Muy bajo \\
\hline 3 & Mexicali & Baja California & & & & 1 & 1 & Muy bajo \\
\hline 37 & Morelia & Michoacán & & & 1 & & 1 & Muy bajo \\
\hline 19 & Nuevo Casas Grandes & Chihuahua & & 1 & & & 1 & Muy bajo \\
\hline 48 & Querétaro & Querétaro & & & 1 & & 1 & Muy bajo \\
\hline 23 & Salamanca & Guanajuato & & & 1 & & 1 & Muy bajo \\
\hline 10 & Saltillo & Coahuila & & & 1 & & 1 & Muy bajo \\
\hline 32 & San Juan de los Lagos & Jalisco & & & 1 & & 1 & Muy bajo \\
\hline 53 & San Lus Potosí & San Luis Potosí & & & 1 & & 1 & Muy bajo \\
\hline 1 & Tecate & Baja California & & & & 1 & 1 & Muy bajo \\
\hline 47 & Tequisquiapan & Querétaro & & & 1 & & 1 & Muy bajo \\
\hline 63 & Tlaxcala & Tlaxcala & & & & 1 & 1 & Muy bajo \\
\hline 71 & Zacatecas & Zacatecas & & & 1 & & 1 & Muy bajo \\
\hline & & Total & 124 & 28 & 208 & 32 & 392 & \\
\hline
\end{tabular}

Tabla 1. Grado de ocurrencia de desastres de municipios con centros turísticos

Fuente: Autor, 2019, basado en DOF del 2000 al 2018 (SEGOB, 2019) e INEGI (2017)

Nota: Las claves corresponden a los municipios representados en la Figura 3

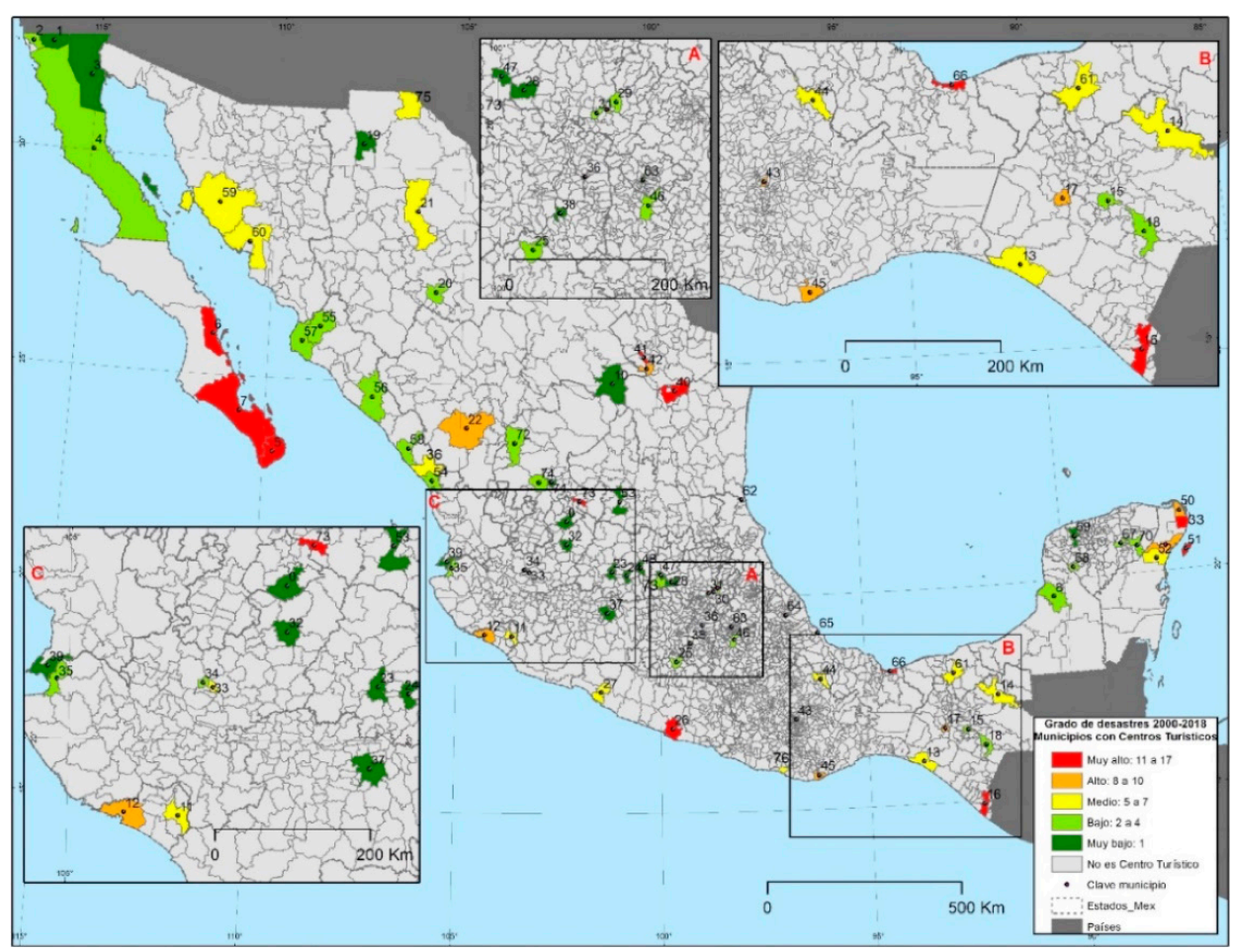

Figura 3. Grado de ocurrencia de desastres en municipios con centros turísticos en México.

Fuente: Autor, 2019, basado en DOF del 2000 al 2018 (SEGOB, 2019) e INEGI (2017)

\section{DISCUSIÓN: DESASTRES, EMERGENCIAS, EXPERIENCIAS Y RESPONSABILIDADES}

Los números no son suficientes para comprender los procesos de construcción y reconstrucción de desastres, muchas veces es necesario contextualizar cualitativamente elementos que permitan dimensionar el manejo de los eventos disruptivos (Calderón, 2001). Si un destino es escenario de constantes emergencias y desastres, significa que la planeación, regional, estatal o municipal fue deficiente, y que en el contexto local algo se está haciendo inadecuadamente. La respuesta en el manejo o gestión del riesgo está en la disminución de las vulnerabilidades, y el aumento de las capacidades de adaptación, o resiliencia. Para ello, es necesario que la prevención sea entendida como un enfoque prospectivo, y no reactivo (FORIN, 2014; Macías, 2017; Maskrey,1993)

En el caso de los centros turísticos en México, la gran mayoría están expuestos a ciclones, huracanes y depresiones tropicales. Lo que implica que existe la posibilidad de que se presente una emergencia, y aunque en algunos casos, la infraestructura esté diseñada para resistir el impacto de algún agente perturbador, la falta de organización interna, y capacitación del personal, puede aumentar o disminuir la tranquilidad de los huéspedes, y con ello mermar la capacidad de 
respuesta. Más aún, si la emergencia se extiende al resto del municipio, y hay afectaciones en los caminos, los aeropuertos, y varios servicios deben suspenderse, el destino no estará listo para recibir a los turistas, y con ello, los daños indirectos se traducen en pérdidas económicas.

\section{Experiencias de emergencias y desastres en destinos turísticos}

Como preámbulo, entre los años 2014 y 2018 este autor colaboró como asesor en la organización de experiencias para una pequeña empresa dedicada a visitar destinos en México: ciudades coloniales, playa, pueblos mágicos, entre otros sitios. En distintos casos, hubo participación en la coordinación de salidas. Por lo cual, existió el contacto directo con distintos actores dedicados al turismo, tales como, empresarios, personal administrativo, guías de turistas, operadores de unidades, y turistas. Entre esas vivencias, se describen dos experiencias en destinos turísticos: una emergencia y un desastre.

\section{El sismo en Zihuatanejo, Gro. Abril de 2014}

Un sismo con epicentro en Tecpan, Guerrero, magnitud 7,2 Mw, ocurrió el 18 abril de 2014, durante las vacaciones de semana santa. Además de la entidad guerrerense, el sismo se sintió en Oaxaca, Veracruz, Ciudad de México, por citar algunas entidades. Minutos posteriores al temblor, autoridades federales descartaron probabilidades de tsunami. Acapulco, destino con un $96 \%$ de ocupación, fue uno de los lugares con mayores escenas de pánico entre los turistas, gente gritando y corriendo despavorida, en algunos casos, los prestadores de servicios apoyaron a tranquilizar a los huéspedes, en otros no.

En esa ocasión la empresa de viajes tenía agendada una visita a Zihuatanejo, Gro., en un hotel que estaba con una ocupación del $90 \%$, a la espera de la llegada de los restantes viajeros. El epicentro del sismo se ubicó a unos $60 \mathrm{~km}$ de Zihuatanejo. Aunque existieran sistemas de alerta temprana, serían ineficaces dada la cercanía a una de las zonas de mayor actividad símica en México, muy cerca de la Brecha de Guerrero, y que especialistas esperan que se produzca un sismo muy fuerte (Aguilar, 2014; Informador, 2014; Tapia-Hernández, 2013).

El hotel referido es amplio, las habitaciones se distribuyen distintas edificaciones de planta baja y primer piso, muy cercanas a la playa, tiene amplios espacios que son utilizados para las cenas y montar espectáculos de los grupos de animación. También cuenta con un estacionamiento, ubicado en la parte más alta del terreno. Una alberca frente al mar, y distintos bares.

La noche previa al sismo, durante el recorrido por las instalaciones, y al platicar con el staff de la empresa, se les indicó que no existían señalamientos o señalética, rutas de evacuación, ni puntos de resguardo, ni que tampoco el personal del hotel informó sobre las acciones a realizar en caso de emergencia. Curiosamente uno de los empleados administrativos escuchó la charla, y comentó que "no debía existir preocupación, que todo estaba bajo control y el personal sabría cómo actuar ante una emergencia".

La mañana del sismo, el restaurante -ubicado en una pequeña loma- estaba ocupado por unas 100 personas. El temblor, dada la magnitud e intensidad, impedía que una persona pudiera ponerse de pie y caminar. La alteración de los huéspedes, acompañó de manera instantánea a la sacudida, ya que algunos integrantes del personal del hotel, en lugar de dar indicaciones para la evacuación ordenada del inmueble, se dedicó a gritar, mientras corrían desesperadamente, empujando a las demás personas, algunos turistas hicieron lo mismo, y otros intentaron calmar a los viajeros alterados. Hubo gente que cayó al suelo y se golpeó, debido a los alimentos y bebidas tiradas por algunos meseros en su escape. Si bien no hubo lesiones graves, se respiraba una atmósfera de intranquilidad y miedo. Entre tantos temores, el de mayor peso, fue la percepción de la ocurrencia de un tsunami. Motivo que alteró aún más a los huéspedes, mientras que los prestadores de servicios no sabían cómo controlar la incertidumbre.

El escenario empeoraba en el sentido de la organización, la desinformación y las más de 100 réplicas que el Servicio Sismológico Mexicano reportó: de entre las cuales por lo menos 5 fueron intensas. Como era evidente, muchos de los huéspedes cancelaron su estadía en el hotel, ya sea por el miedo a un sismo de mayor intensidad, otros, por las afectaciones en sus habitaciones, que incluían daños ligeros, como cuadros, espejos y vidrios rotos, como televisores dañados, baños con tuberías rotas, y aires acondicionados descompuestos: elementos que, si bien no impedían utilizar las habitaciones, no eran cómodas dados los $30^{\circ}$ Celcius de temperatura. Aunque el personal no era culpable de las múltiples réplicas, si tenía alguna responsabilidad en la preparación, ante inminentes réplicas, además de haber sido rebasado en su capacidad de respuesta, para atender las múltiples quejas. 
Aunque el hotel contaba con personal de mantenimiento y limpieza, fueron también rebasados dada la cantidad de pequeños daños en las habitaciones. La fila de cancelaciones superaba las 50 habitaciones. El personal administrativo, fue superado igualmente. Nunca habían experimentado una situación parecida. En ese caso, el staff de la empresa de turismo contactó de manera inmediata a los viajeros, brindó la información necesaria para despejar dudas y controlar inquietudes. Se tomó la decisión de quedarse en el hotel, ya que no existían razones para huir del destino. En ese sentido, un par de habitaciones fueron afectadas, pero se hizo un reacomodo.

A raíz de esa experiencia, la empresa presentó inquietudes cuando se hospedaba en hoteles de Guerrero, Oaxaca, y Chiapas, destinos con alta ocurrencia de sismos. Por lo cual, como parte del protocolo, una vez en el destino, se contacta a la brigada de protección civil. Debido a que los viajeros no necesariamente están todo el tiempo en los hoteles, se les solicita un número móvil, y datos para contactar a un familiar o conocido en caso de emergencia, el tipo de sangre, alergias a medicamentos. Entre otras cosas.

\section{El sismo del 19 de septiembre de 2017}

Justamente el día que se cumplían 32 años del sismo de 1985, el 19 de septiembre de 2017, ocurrió un sismo de 7,1 Mw, con epicentro en Morelos. En el caso de la capital del país mexicano, la ocupación hotelera disminuyó entre un 20 y hasta un 70\% como producto del temor entre los turistas a la ocurrencia de más sismos. De 300 hoteles en la Ciudad de México, un $7 \%$ tuvo que cerrar: $2 \%$ por daños estructurales, y un $5 \%$ estaban a la espera de dictamen. El presidente de la Asociación Mexicana de Hoteles y Moteles declaró que los efectos de las cancelaciones se podrían extender hasta tres meses, por lo cual, algunos hoteles en destinos afectados y no afectados por el sismo, aplicaron tarifas de hasta un 50\% de descuento (Ballesteros, 2017).

Uno de los muchos lugares afectados fue Tlayacapan, Morelos, considerado entre los 111 Pueblos Mágicos que tiene México. Entre sus diversos atractivos está el Ex Convento de San Juan Bautista que data de 1534 y fuera casa de visita de Hernán Cortes, además de múltiples productos de barro elaborados por artesanos (SECTUR, 2017a). Ante la falta de apoyo por parte de las autoridades, la población pedía ayuda a sus conocidos. Es así como uno de los artesanos, con quien la empresa realizaba actividades en Tlayacapan, solicitó de manera urgente ayuda, ya que su casa había colapsado. El personal de la empresa colaboró para acopiar víveres, mismos que trasladaron de la Ciudad de México a Tlayacapan: cabe señalar que muchos de los viajeros de la empresa se unieron a esta noble causa. Una vez en el lugar del desastre, se procedió a entregar las despensas. Una reflexión personal fue: las despensas quitaron el hambre, pero no disminuyeron el riesgo de nuevos desastres.

La catástrofe fue tan grande que quienes fueron a entregar los víveres se unieron a la población para remover los escombros: literalmente piedra por piedra. Según fuentes directas, más de 630 casas fueron afectadas, 300 con daño parcial (bardas caídas), 230 con agrietamientos; y cerca de 100 en pérdida total. Muchas de ellas eran de artesanos. Como en el caso de la Ciudad de México, la actividad turística se redujo considerablemente. En los medios de comunicación se mostraban imágenes de la tragedia. Inclusive, debido al daño, el Ex convento antes referido -el mayor atractivo de la localidad- tuvo que cerrar sus puertas. Hasta la fecha el proceso de reconstrucción de los atractivos turísticos es lenta, siendo responsabilidad de los gobiernos federal y estatal (Delgado, 2017).

Ante la impresión del evento, el personal de la empresa turística quería apoyar de otra forma a los artesanos afectados. Es así como surgió la idea de comprarles las piezas de barro que no estuvieran dañadas y venderlas en la Ciudad México. Si bien no fueron montos exorbitantes, la ayuda llegó directamente a algunas familias afectadas.

Como declaró el presidente de la Confederación de Organizaciones Turísticas de América Latina en $2017^{2}$ : ante un desastre lo más importante es reactivar la economía local. Es un punto de quiebre, porque algunas familias que pierden su patrimonio, optan por pedir ayuda y estar a expensas de ello, volviéndose más vulnerables, o reconstruirse asímismos y seguir adelante, es decir, hasta cierto punto hacerse resilientes.

Ante ese sismo, en cuestión de segundos, la vida de muchas personas vinculadas al turismo cambió. Además del caso de Tlayacapan, la empresa tenía programados viajes a la zona de balnearios ubicados cerca de Cuautla, en Morelos, y otro en la Ciudad de Puebla. En ambos casos

2. Noticias en TV Milenio entre el $7 \mathrm{y}$ el 20 de septiembre de 2017 . 
fueron cancelados: En el primero porque tras el sismo, el flujo de aguas termales que nutría a un balneario se redujo considerablemente, hasta motivar al dueño a cerrar las instalaciones de un patrimonio que llevaba varias décadas de uso. A un mes del sismo, tuvo que verse en la necesidad de no requerir los servicios de distintos empleados, e inclusive los negocios que vendían comida, o productos de natación, también cerraron. En el segundo caso, los guías de turistas y personal de un hotel del centro, declararon que estaban en condiciones de recibir a los viajeros, sin embargo, la propia dependencia de turismo estatal sugirió a la empresa no realizar la visita, ya que los daños en iglesias y distintas edificaciones propiciaron el cierre de vialidades y generaba más tráfico vehicular que del habitual.

A dos meses del sismo, de los 400 inmuebles catalogados por el Instituto Nacional de Antropología e Historia (INAH) con valor histórico y cultural en el estado, el $87 \%$ sufrieron daños y estaban cerrados al público, incluida la Ruta de Conventos (como el de Tlayacapan), aseveró la Secretaría de Turismo de Morelos (Valle, 2017).

Expertos en geología y geofísica de la UNAM señalaron que el sismo alteró el curso de los afluentes y disminuyó el volumen de agua de algunos manantiales. En el caso de Agua Hedionda, antes del sismo brotaban 860 litros de agua por segundo, después del sismo fueron 20 litros. Tras un año y con sistemas de bombeo, el brote es de 150 litros. De 46 balnearios ubicados en Morelos, un $32 \%$ tuvo afectaciones, por lo cual mermó la economía de la región, del municipio, y de múltiples familias que dependían del turismo. Aunque existen apoyos financieros por parte del gobierno estatal, estos no son suficientes para resolver el problema (Hernández, 2018; Miranda, 2017).

\section{La agencia busca ser menos vulnerable y más resiliente}

Ante los eventos referidos y otros más que se suscitaron en la empresa, los directivos decidieron, capacitar a todo el personal en materia de protección civil y primeros auxilios básicos. Buscaban la contratación de seguros adicionales para los viajeros. Previo a cada salida, son llenados formularios con datos de contacto en caso de emergencia, tipo de sangre, padecimientos y alergias. En las salidas, se les pide que estén acompañados de otro viajero, para poder contactarlos vía telefónica. Los operadores de los autobuses mantienen comunicación con colegas que muchas veces están en los mismos destinos. De esta manera la empresa busca identificar sus niveles de vulnerabilidad económica, administrativa y organizacional, y en caso de una emergencia, reducir al máximo los posibles daños. E inclusive tiene la libertad de elegir si ante un evento natural extremo, debe hacer cambios en los itinerarios o rutas, al final, trata de anticiparse a los peligros sin dejar de lado sus compromisos con los viajeros. La experiencia previa le será de utilidad para futuras eventualidades.

Las experiencias ante emergencias y desastres dejan aprendizajes significativos, que deben formar parte de la capacitación de los prestadores de servicio. Ya que la toma de decisiones a veces requiere segundos, por ello, la comunicación del riesgo es uno de los elementos más importantes. Oropeza (2018) menciona que, durante una emergencia, la ayuda tardará en llegar algunos minutos, o nunca llegará. Esa diferencia de tiempos puede ser vital: cuando una persona deja de respirar, si no recibe primeros auxilios, en 6 minutos estará en condición de muerte vegetal, pasados 12 minutos podría morir. Es obligación de los inmuebles o medios de transporte, dotar de seguridad a todos los huéspedes, visitantes y personal.

\section{Implicaciones en materia de protección civil}

Para Macías (1999) "la prevención de desastres es un asunto que atañe a toda la sociedad, y hay responsabilidades y obligaciones diferenciales" (Macías, 1999, p.19). Si bien las autoridades sobresalen entre los distintos actores, no son las únicas encargadas de la prevención. Ya que ante una emergencia las acciones y medidas previas incidirán en los efectos positivos y negativos que se desarrollen en el presente y en el futuro, la prevención debe ser, por lo tanto, prospectiva y no reactiva.

Toscana (2011) ha dado a conocer algunos problemas que subyacen en materia de protección civil, tales como distanciamientos entre instituciones y población, además de incompetencia en planeación urbana. Si bien, en ningún momento se argumenta que todo el sistema es ineficiente, han sido registrados diversos casos que demuestran los problemas al interior, traducidos en falta de recursos humanos, económicos, capacitación, inadecuados perfiles, entre tantos otros que, en caso de emergencia o desastres, salen a relucir y se extienden a los destinos turísticos. 


\section{Ley General de Protección Civil}

Una de las finalidades que enmarca la Ley General de Protección Civil en México, es la autoprotección, y esta depende de los conocimientos que una persona tenga sobre los 'agentes perturbadores' a su alrededor, además de las 'medidas estructurales' y 'no estructurales' que se entrelacen para garantizar su seguridad. Cabe recordar que el desconocimiento de esta ley no exime a la población su cumplimiento. Se mencionan 4 artículos acordes al sector turístico en México.

"Artículo 4. El fomento de la participación social para crear comunidades resilientes, capaces de resistir los efectos de los desastres, para recuperar en el menor tiempo posible sus actividades".

(LGPC, 2018, p.8)

"Artículo 10. La Gestión Integral de Riesgos considera las siguientes fases anticipadas a la ocurrencia de un agente perturbador: Conocimiento del origen y naturaleza de los riesgos, además de los procesos de construcción social de los mismos; Identificación de peligros, vulnerabilidades y riesgos, así como sus escenarios; Análisis y evaluación de los posibles efectos; Revisión de controles para la mitigación del impacto; Acciones y mecanismos para la prevención y mitigación de riesgos; Desarrollo de una mayor comprensión y concientización de los riesgos, y Fortalecimiento de la resiliencia de la sociedad".

(LGPC, 2018, p.10)

"Artículo 15, El objetivo general del Sistema Nacional es el de proteger a la persona y a la sociedad y su entorno ante la eventualidad de los riesgos y peligros que representan los agentes perturbadores y la vulnerabilidad en el corto, mediano o largo plazo, provocada por fenómenos naturales o antropogénicos".

(LGPC, 2018, p.11)

"Artículo 78. Los particulares que por su uso y destino concentren o reciban una afluencia masiva de personas, están obligadas a contar con una unidad interna de protección civil y elaborar un programa interno, en los términos que establezca esta Ley y su reglamento, sin perjuicio de lo señalado en los respectivos ordenamientos locales".

(LGPC, 2018, p.28)

Los programas internos de protección civil podrán atender a alguno o varios de los siguientes criterios: Aforo y ocupación; Vulnerabilidad física; Magnitud del riesgo de incendio que posee un inmueble o instalación; Condiciones físicas de accesibilidad de los servicios de rescate y salvamento; Tiempo de respuesta de los servicios de rescate y salvamento; Condiciones del entorno, entre otros que pudieran incrementar el riesgo.

\section{Responsabilidades en los destinos turísticos en protección civil}

Con base en la LGPC, además las experiencias narradas en la anterior sección, sumada a los antecedentes en materia de desastres en centros turísticos, se entrevistó a un experto ${ }^{3}$ en atención a emergencias y desastres, quien suma 20 años de experiencia, tanto en la capacitación de personal, como en la elaboración de planes internos de protección civil.

En el sector turismo, la responsabilidad de los hoteles es ser autosuficientes y tener identificado su grado de exposición ante uno o varios agentes perturbadores. Esto les permite tomar las decisiones más adecuadas para el manejo de una emergencia. Existen tres escenarios: 1) El hotel está dañado y debe ser desalojado; 2) El hotel no está dañado, pero las vías de comunicación, drenaje, agua potable y energía eléctrica, sí; 3) El hotel sigue en pie, e inclusive pudiera funcionar como un refugio temporal para otros hoteles afectados en la zona.

En este sentido un hotel podría considerarse resiliente si tiene la capacidad de seguir en operaciones, durante el paso del evento extremo, y aunque existan afectaciones, estas pueden ser arregladas. Si bien las emergencias son un caso extremo, los acontecimientos de menor peso, como una persona fracturada o quemada, puede ser un indicio de la capacidad de atención y respuesta. Según la LGPC, cualquier infraestructura con afluencia de personas debe estar organizada para resolver la emergencia, contar con personal entrenado, brindar primeros auxilios, búsqueda y rescate, mientras llega la ayuda externa.

3. Justamente a quien diera la capacitación en materia de protección y primeros auxilios básicos, en la agencia de viajes. 
Una empresa que está organizada a su interior en materia de protección civil, que realiza simulacros ante múltiples agentes perturbadores, puede dar una respuesta rápida ante cualquier emergencia, esto influye en la imagen corporativa, y permite que un simple incidente no escale a una emergencia, y de una emergencia, a un desastre. El personal en los centros turísticos debe saber cómo detener la evolución de esos incidentes que pudieran terminar en repercusiones legales, desde multas, clausuras, o demandas de las personas afectadas. El máximo beneficio de incorporar estas medidas no estructurales se traduce en el ahorro de millones de pesos, que se pueden gastar en asegurar tanto infraestructura, como al personal que labora, y visita estos destinos. El experto Oropeza menciona, que entre más incidencias de accidentes existan en una empresa, mayor será la tasa que paguen por su seguro, derivado del índice de riesgo laboral, medible a través de bases de datos de atención a emergencias. En su opinión, que coincide con la de otros autores como Vera Cortés (2009), Wilchaes-Chaux y Oliver-Smith en FORIN (2014), se pone más atención en la reacción, cuando la emergencia es inminente, dejando de lado a la prevención, vista como un elemento a futuro. También en muchos casos, los tomadores de decisiones no cumplen con un perfil adecuado, y no pueden implementar las medidas básicas de atención.

\section{CONCLUSIONES}

\section{El bono de desastres}

En octubre de 2012, México junto con Chile, Colombia y Perú -integrantes de la Alianza del Pacífico-, contrataron el Bono Catastrófico Colectivo (Multicad), con renovaciones cada 2 años. En 2018 se firmó un bono por $\$ 260$ millones de USD, este se activa cuando una agencia externa confirma ciertos datos en materia de sismos o huracanes: se localizan en las zonas preestablecidas (ver Figura 4 y 5); y la profundidad de sismos o la presión atmosférica del ojo del huracán se encuentran dentro de los rangos establecidos. Las críticas hacia estas medidas no se han hecho esperar, señalándose que el bono debiera estar suscrito por daños y no por magnitudes, además en algunos desastres, hay municipios con severos daños que, por falta de conocimiento de sus autoridades para realizar la declaratoria, se quedan sin apoyo (Albarrán, 2018; Flores, 2018; Ruíz, 2012).

En el caso de los sismos, hay 5 zonas (ver Figura 4). El bono depende de la zona del epicentro, magnitud y profundidad, pero no de los daños. Antes del 19 de septiembre de 2017, el bono cubría sismos superiores a 8,0 Mw. El bono se activó para el sismo del 7 de septiembre de 2017: y México accedió a $\$ 150$ millones de USD, no así para el del 19 de septiembre.

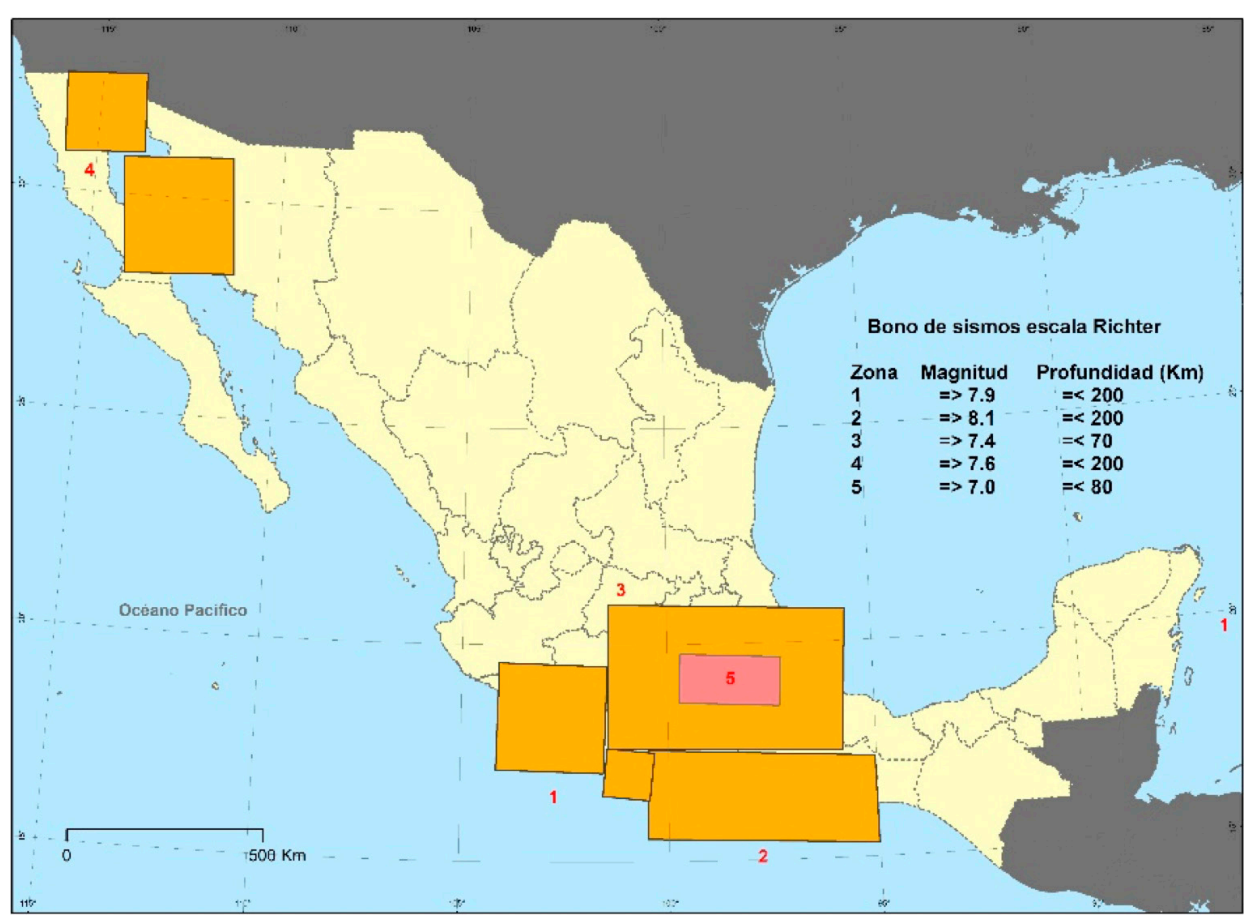

Figura 4. Cobertura del fondo catastrófico de desastres por sismos en México Fuente: Autor, 2019, basado en en Albarrán (2018) 


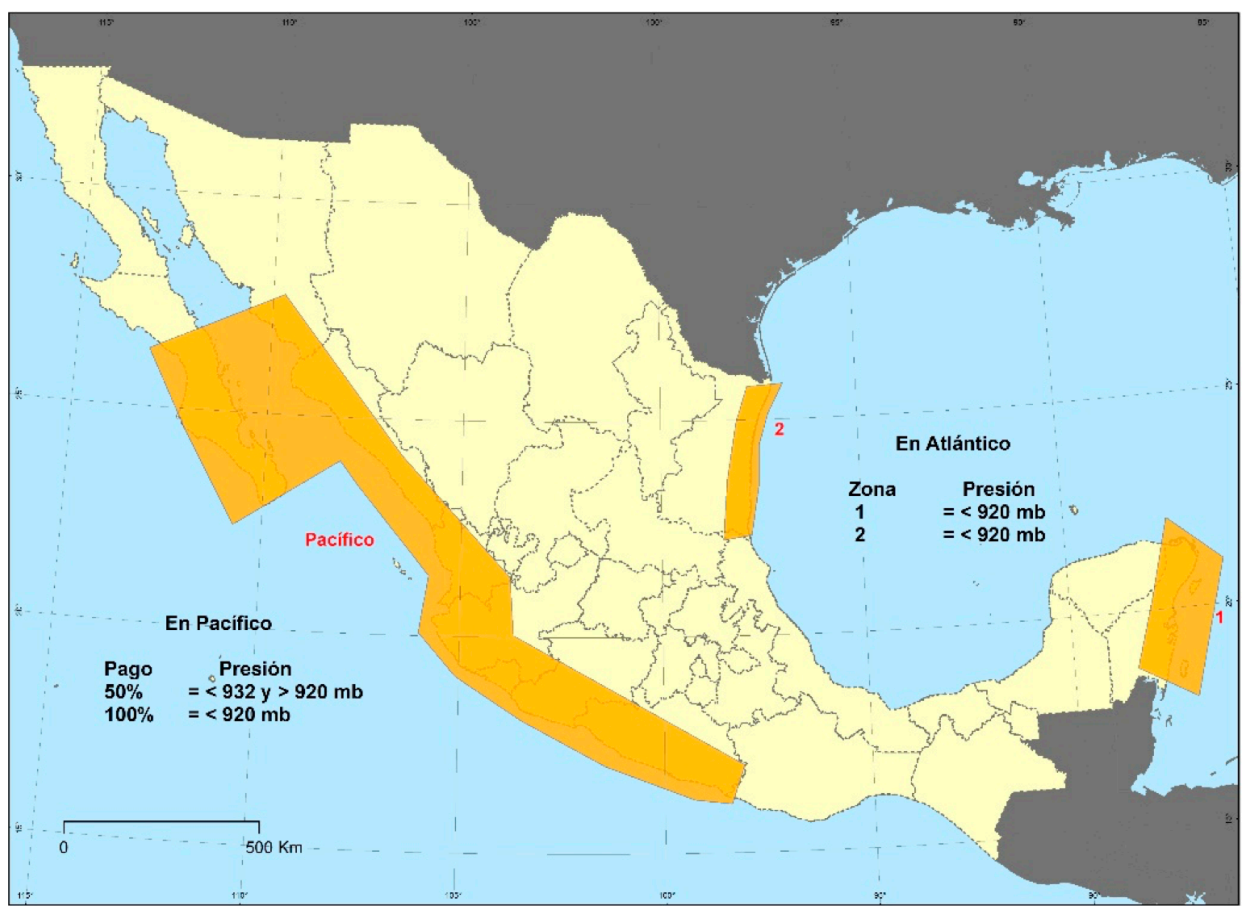

Figura 5. Cobertura del fondo catastrófico de desastres por huracanes en México Fuente: Autor, 2019, basado en en Albarrán (2018)

En materia de huracanes, hay 3 zonas (ver Figura 5). El bono depende la zona del meteoro, la categoría del huracán y la presión del ojo.

Si las actuales reglas del Multicad hubiesen aplicado desde 2000 al 2018, de los 392 desastres acontecidos en 77 municipios con centros turísticos referidos en la primera parte, se tendrían lo siguiente:

- Sismos: 32 declaratorias de desastres. Pese a que los daños en 4 eventos superaron los $\$ 900$ millones de USD: en ninguno de los casos se hubiese podido acceder a los recursos.

- Huracanes: 46 declaratorias de desastres. Con acceso a recursos: Wilma, 2005: 882 mb, accedería al 100\% del pago. Sin acceso: Stan, 2005: 976 mb; Ingrid, 2013: 986 mb; Manuel, 2013: 985 mb; Odile, 2014: 941 mb. La gran mayoría de desastres en municipios con centros turísticos se debió a tormentas tropicales y no a huracanes.

\section{Centros turísticos en México: vulnerabilidad y resiliencia}

Según lo observado en este trabajo, la relevancia de comprender los procesos de desastre en destinos turísticas consiste en: 1) Los visitantes y algunos prestadores de servicios presentan distintos grados de exposición; 2) Los visitantes y algunos prestadores de servicios no conocen los planes y protocolos ante una posible emergencia; 3) La infraestructura de los destinos llega a ser deficiente; 4) En caso de desastre la atención se concentra en 'rescatar' a los turistas varados y esperar a que sea levantada la declaratoria. 5) Los apoyos de los gobiernos muchas veces llegan a ser ineficientes; 6) La aseguranza, o transferencia de riesgos, debe realizarse con base en daños y no en condiciones físicas de eventos naturales; 7) Primero se debe reducir la vulnerabilidad organizacional, económica, entre otras, y después incorporar acciones de resiliencia.

Aunque la Ley General de Protección Civil enfatiza en la necesidad de promover una cultura de prevención, está se concentra en la reacción a emergencias inminentes. En gran medida se deduce que esta ambigüedad es resultado de la escasa presencia de contenidos educativos en materia de riesgos de desastres, en todos los sectores educativos del país, siendo que son pocas las asignaturas -como en Geografía- donde los estudiantes, futuros tomadores de decisiones, aprenden medidas de prevención.

Es conocida la complejidad de comunicar a una autoridad, o a la población en general, conceptos complejos como el riesgo, cuanto estos están lejos de lo cotidiano. Pese a lo anterior, la LGPC señala que los desastres deben ser comprendidos como procesos de construcción social. De esta manera, se debe trabajar en cuatro segmentos: 1) Autoridades; 2) Prestadores de servicios; 3) 
Turistas y; 4) Medios de comunicación. Para informarlos sobre las diferencias entre vulnerabilidad y resiliencia, y asuman un papel activo en la construcción de estrategias y acciones que incrementen las medidas preventivas que pudieran reducir los riesgos.

Aunque los grandes desastres no se presentan con regularidad, generan cuantiosos daños y merman la llegada de turistas entre un 40 y un $80 \%$, a veces por periodos entre 3 y hasta 12 meses, en función de los recursos, apoyos y estrategias de reconstrucción. En este sentido, ignorar los riesgos potenciales, es aventurarse a invertir recursos que pudieran perderse en cuestión de minutos u horas. También, en muchos de los casos, la especulación y la desinformación, exacerba los daños y permea en la percepción de riesgo, lo cual motiva a los turistas a no visitar las zonas afectadas. Por lo anterior, debe prevalecer el trabajo colaborativo entre empresas, prestadores de servicios, autoridades de los distintos órdenes de gobierno, medios de comunicación, el sector educativo, y especialistas en desastres

\section{AGRADECIMIENTOS}

A la Dra. Naxhelli Ruíz por su apoyo metodológico en materia de desastres. A Octavio Salazar Oropeza por sus aportaciones en materia de protección civil. A la empresa Buscame\&Travel, por permitirme conocer múltiples destinos en México. A Juan Toscano, por compartir sus vivencias frente al sismo en Tlayacapan, Morelos.

\section{REFERENCIAS}

Aguilar, R. (18 de abril, 2014). Sismo provoca pánico en Guerrero; Acapulco al $96 \%$ de ocupación.

Excélsior. Recuperado de: https://www.excelsior.com.mx/comunidad/2014/04/18/954631 [visitado el 5 de enero de 2019]

Albarrán, E. (8 de febrero, 2018). Bono catastrófico tiene dos coberturas. El Economista. Recuperado en: https://www.eleconomista.com.mx/sectorfinanciero/Bono-catastrofico-tiene-doscoberturas-20180208-o112.html [visitado 4 de enero de 2019]

Ballesteros, C. (27 de septiembre de 2017). El terremoto golpea el sector turístico mexicano. El País. Recuperado de: https://elpais.com/internacional/2017/o9/27/mexico/1506483655_938716.html [visitado 27 de noviembre de 2018]

BBC. (23 de diciembre, 2018). Tsunami en Indonesia: cómo un volcán puede generar una ola mortal. $B B C$ News. Recuperado de: https://www.bbc.com/mundo/noticias-internacional-46663165 [visitado 3 de enero de 2019]

Blakie, P., Cannon, T., Davis, I. \& Wisner, B. (1996). Vulnerabilidad. El entorno social, político y económico de los desastres. Bogotá: Tercer Mundo Editores.

Bündnis Entwicklung Hilft BEH \& United Nations University Institute for Environment and Human Security UNU-EHS. (2018). World Risk Report 2018. Berlin \& Bochum: BEH. Recuperado de: https://reliefweb.int/sites/reliefweb.int/files/resources/WorldRiskReport-2018.pdf [visitado el 5 de enero 2019]

Calderón, A. (2001). Construcción y reconstrucción del desastre. Ciudad de Mexico: Editorial Plaza y Valdez.

Calderón, A. (2011). Lo ideológico de los términos en los desastres, Revista Geográfica de América Central, 2(2), 1-16.

Delgado, A. (20 de septiembre, 2017). El sismo arrasó con el templo de San Juan Bautista, Tlayacapan, considerado patrimonio de la humanidad. Proceso. Recuperado de: https://www.proceso.com. $\mathrm{mx} /$ 504221/sismo-arraso-templo-san-juan-bautista-tlayacapan-considerado-patrimonio-lahumanidad [visitado el 22 de septiembre de 2017]

El Universal. (8 de septiembre, 2017a). Cinco huracanes que más daños han dejado a México. El Universal. Recuperado de: https://www.eluniversal.com.mx/estados/los-cinco-huracanes-que-masdanos-han-dejado-mexico [visitado 18 de noviembre de 2018]

El Universal. (2 de octubre, 2017b). Pueblos mágicos fracturados tras los sismos. El Universal. Recuperado de: http://www.eluniversal.com.mx/estados/pueblos-magicos-fracturados-tras-lossismos [visitado 20 de diciembre de 2018]

Instituto Nacional de Estadística, Geografía e Informática INEGI. (2018). Empleo y ocupación en México. INEGI [online]. Recuperado de: http://www.beta.inegi.org.mx/temas/empleo/ [visitado el 2o de septiembre de 2018] 
Esquivel, G., Arredondo, I. \& Serdán, R. (2018). Sismos 2017: Diagnósticos y propuestas para la reconstrucción. Ciudad de México: Instituto Belisario Domínguez.

Flores, L. (15 de octubre, 2017). México firma acuerdo para Bono Catastrófico. El Universal. Recuperado de: http://www.eluniversal.com.mx/nacion/sociedad/mexico-firma-acuerdo-para-bono-catastrofico [visitado 3 de enero de 2019]

FORIN. (2014). FORIN: Investigaciones Forenses de Desastres relacionadas con la ocurrencia de Deslizamientos. Curso-Taller Internacional realizado en el Instituto de Geografía, UNAM, México DF, 24-25 de febrero.

Hernández, R. (19 de septiembre, 2018). Lenta recuperación de Agua Hedionda. El Sol de Cuernavaca. Recuperado de: https://www.elsoldecuernavaca.com.mx/local/lenta-recuperacion-de-aguahedionda-2006186.html [visitado 23 de diciembre de 2018]

Informador. (18 de abril, 2014). Vacacionistas en Acapulco, sin riesgo tras sismo. Informador. Recuperado de: https://www.informador.mx/Mexico/Vacacionistas-en-Acapulco-sin-riesgo-trassismo-20140418-0o67.html [visitado 25 de noviembre de 2018]

La silla rota. ( 5 de junio de 2018) ¿Cómo impactó al turismo la erupción del volcán en Guatemala? $L a$ silla rota. Recuperado de: https://lasillarota.com/como-impacto-al-turismo-la-erupcion-del-volcanen-guatemala/226658 [visitado 4 de enero de 2019]

Ley General de Protección Civil LGPC. (2018). Diario Oficial de la Federación (Última Reforma), México, 19 de enero de 2018.

Ley General de Turismo. (2018). Diario Oficial de la Federación (Última Reforma), 19 de enero de 2018.

Macías, J.M. (1999). Desastres y protección civil: problemas sociales, políticos y organizacionales. Ciudad de México: Ciesas.

Macías, J.M. (2017). Diálogos de la comunidad. Desastres más allá de la respuesta. En Panel de Discusión Multidisciplnaria. Instituto de Geografía, UNAM, 10 de octubre.

Maskrey, A. (1993). Los desastres no son naturales. Quito: Red de Estudios Sociales en Prevención de Desastres en América Latina LA RED.

Miranda, J. (21 de octubre, 2017). En Morelos, el sismo sacudió las capas subterráneas y dejó sin agua a balnearios. El Universal. Recuperado de: https://www.eluniversal.com.mx/estados/en-morelos-elsismo-sacudio-las-capas-subterraneas-y-dejo-sin-agua-balnearios [visitado 23 de diciembre de 2018]

Notimex (17 de abril, 2018). 10 millones de mexicanos ya viven del turismo. El Economista. Recuperado de: https://www.eleconomista.com.mx/empresas/Sectur-10-millones-de-mexicanos-ya-viven-delturismo-20180413-0085.html [visitado el 10 de agosto de 2018]

Oropeza, O. (2018). Entrevista realizada por Felipe Juárez el 20 de agosto de 2018 vía telefónica. Duración 45 minutos.

Ruíz, N. (2012). La definición y medición de la vulnerabilidad social. Un enfoque normativo, Investigaciones Geográficas, 77, 63-74. Recuperado de: http://ref.scielo.org/fpjr5d [visitado el 5 de febrero de 2019]

Sanchis, R., \& Poler, R. (2011). Medición de la resiliencia empresarial ante eventos disruptivos. una revisión del estado del arte. In V International Conference on Industrial Ingineering and Industrial Management, Cartagena (Col.), 7-9 de Septiembre. Recuperado de: http://adingor.es/congresos/ web/uploads/cio/cio2o11/administracion_de_empresas/104-113.pdf [visitado el 15 de diciembre de 2018]

Secretaría de Gobernación SEGOB. (2019). Diario Oficial de la Federación DOF. SEGOB. [online] Recuperado de: https://www.dof.gob.mx/busqueda_detalle.php [visitado el 19 de Feb. 2019]

Secretaría de Turismo SECTUR. (2017a). Atlas Turístico de México. SECTUR [online]. Recuperado en: http://atlasturistico.sectur.gob.mx/AtlasTuristico/bienvenido.do [visitado el 7 de enero de 2018]

Secretaría de Turismo SECTUR. (2017b). Monitoreo Data Tur. SECTUR [online]. Recuperado de: http:// www.datatur.sectur.gob.mx [visitado 19 de julio de 2017]

Secretaría de Turismo SECTUR. (2018). Glosario de términos en materia de turismo. SECTUR [online]. Recuperado de: http://www.datatur.sectur.gob.mx/SitePages/Glosario.aspx [visitado el 6 de septiembre de 2018]

Spring, Ú.O. (2012). Vulnerabilidad Social en Eventos Hidrometeorológicos Extremos: Una Comparación entre los huracanes Stan y Wilma en México, Revista Internacional de Ciencias Sociales y Humanidades SOCIOTAM, 12(2), 125-146. 
Tapia-Hernández, E. (2013). Observaciones sobre la predicción de sismos: una visión actual, Revista Internacional de Desastres Naturales, Accidentes e Infraestructura Civil, 13(2), 255-271.

Toscana, A.T. (2011). Protección civil, población, vulnerabilidad y riesgo en Santiago Miltepec, Toluca, Investigaciones Geográficas, 74, 35-47.

Valle, A. (13 de noviembre, 2017). Así libra el turismo de Morelos el 19S. Expansión. Recuperado de: https://expansion.mx/empresas/2017/11/12/asi-libra-el-turismo-de-morelos-el-19s [visitado 27 de noviembre de 2018]

Vera Cortés, G. (2009). Totonacapan, 1999: El año de la Bestia. En Vera Cortés, G. (Ed.) Devastación y éxodo. Memoria de seminarios sobre reubicaciones por desastres en México. Ciudad de México: CIESAS, pp. 59-80.

Vila M., D. (2015). El huracán Odile y sus efectos en la infraestructura del sur de la península de Baja California. Ciudad de México: Instituto de Ingeniería, UNAM.

Wilches-Chaux, G. (1998). Auge, Caída y Levantada de Felipe Pinillo, Mecánico y Soldador o Yo Voy a Correr el Riesgo. Quito: Red de Estudios Sociales en Prevención de Desastres en América Latina. LA RED. 